Journal of

Molecular Microbiology

and Biotechnology
J Mol Microbiol Biotechnol 2011;20:83-95

DOI: $\underline{10.1159 / 000324505}$

Published online: March 22, 2011

\title{
Evolution of Patchily Distributed Proteins Shared between Eukaryotes and Prokaryotes: Dictyostelium as a Case Study
}

\author{
Jan O. Andersson \\ Department of Molecular Evolution, Evolutionary Biology Center, Uppsala University, Uppsala, Sweden
}

\section{Key Words}

Lateral gene transfer $\cdot$ Protist evolutionary genomics ·

Gene acquisition $\cdot$ Gene loss

\begin{abstract}
Protein families are often patchily distributed in the tree of life; they are present in distantly related organisms, but absent in more closely related lineages. This could either be the result of lateral gene transfer between ancestors of organisms that encode them, or losses in the lineages that lack them. Here a novel approach is developed to study the evolution of patchily distributed proteins shared between prokaryotes and eukaryotes. Proteins encoded in the genome of cellular slime mold Dictyostelium discoideum and a restricted number of other lineages, including at least one prokaryote, were identified. Analyses of the phylogenetic distribution of 49 such patchily distributed protein families showed conflicts with organismal phylogenies; 25 are shared with the distantly related amoeboflagellate Naegleria (Excavata), whereas only two are present in the more closely related Entamoeba. Most protein families show unexpected topologies in phylogenetic analyses; eukaryotes are polyphyletic in $85 \%$ of the trees. These observations suggest that gene transfers have been an important mechanism for the distribution of patchily distributed proteins across all domains of life. Fur-
\end{abstract}

ther studies of this exchangeable gene fraction are needed for a better understanding of the origin and evolution of eukaryotic genes and the diversification process of eukaryotes.

Copyright $\odot 2011$ S. Karger AG, Basel

\section{Introduction}

Only a small minority of all protein families is present in all living organisms [Charlebois and Doolittle, 2004; Ciccarelli et al., 2006], and the number of families present in the environment is larger than the number of genes in any extant genome. Lapierre and Gogarten [2009] explored this phenomenon and analyzed the presence and absence of gene families in 573 bacterial genomes. Three sets of genes were identified based on their frequencies of appearance: core genes, character genes and accessory genes. Proteins encoded by core genes are widely distributed and perform the basic common functions in cells. Character genes are rarer and for example enable the colonization of certain niches. Accessory genes are patchily distributed and found only in a few genomes and encode for functions that distinguish species and strains [Lapierre and Gogarten, 2009]. It is widely assumed that lateral gene transfer (LGT) is the main mechanism to distribute character and accessory genes among prokaryotes

\section{KARGER \\ Fax +41613061234 E-Mail karger@karger.ch} www.karger.com

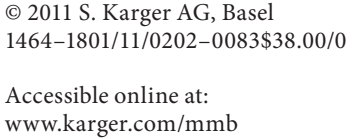

Jan O. Andersson

Department of Molecular Evolution, Evolutionary Biology Center

Uppsala University

Norbyvägen 18C, SE-752 36 Uppsala (Sweden)

Tel.+46 18471 4696, E-Mail jan.andersson@ebc.uu.se 
[Bapteste et al., 2009; Dagan and Martin, 2007], whereas vertical inheritance is the main mechanism for maintaining the core genes in the genomes [Ciccarelli et al., 2006]. However, the impact of gene transfer on gene family dynamics in the evolution of microbial eukaryotes is still controversial [Bapteste et al., 2009]. Here, the author presents a case study of the evolution of patchily distributed proteins in a eukaryotic genome that suggests that gene transfer is a major evolutionary mechanism of distribution of accessory and character also in microbial eukaryotes.

Studies of LGT affecting eukaryotes have typically used phylogenomic approaches. Unexpected topologies with eukaryotes branching with prokaryotes have been identified among a large number of trees. These approaches have been effective in identifying LGT as a putatively important mechanism in eukaryotic genome evolution [Andersson, 2009a; Andersson et al., 2003, 2007; Archibald et al., 2003; Bowler et al., 2008; Carlton et al., 2007; Hall et al., 2005; Huang and Gogarten, 2008; Keeling and Palmer, 2008; Loftus et al., 2005; Nosenko and Bhattacharya, 2007; Ricard et al., 2006; Richards et al., 2006]. Many of these transfers are within patchily distributed protein families, typically present only in a few eukaryotic and prokaryotic lineages. However, phylogenomic approaches do not necessarily give balanced information about the frequencies of gene transfer for these genomes, because a failure to pass all the filters applied does not necessarily indicate that an individual gene family has evolved strictly via vertical inheritance. Another limitation for the studies of LGT, especially for accessory and character genes, is the limitation of data; there are only sequence information from a tiny fraction of the microbial diversity [Andersson, 2009b].

A circumstantial indication that we currently underestimate the impact of LGT on patchily distributed protein families in eukaryotic genome comes from a metagenomic study. Almost 300,000 clusters of protein sequences based on primary sequence similarity were found in a metagenomic project of ocean water [Yooseph et al., 2007]. Unexpectedly, many protein families previously only detected in eukaryotic organisms were found in prokaryotic organisms in the ocean, hinting at an important role of inter-domain gene transfer in the ocean. Unfortunately, the uncertainty of the taxonomic origin of individual sequences within metagenomic data precludes more detailed studies of LGT within this dataset.

This case study uses an approach in which gene families are included based on their phylogenetic distribution, rather than the topology of the phylogenetic trees. The intention is not primarily to determine the impact of gene transfer in any particular eukaryotic genome. The genome of the social amoeba Dictyostelium discoideum is selected as a case study because it is completely sequenced [Eichinger et al., 2005] with a well-maintained genome database (http://dictybase.org/), and because the slime mold has not been identified as a protist for which LGT is unusually common using other approaches [Eichinger and Noegel, 2005; Watkins and Gray, 2006]. The distribution of the members of each of these families across the tree of life were analyzed, and complemented with phylogenetic analyses to distinguish LGT scenarios from gene duplication and losses. If gene transfer is rare in eukaryotic genome evolution, the patchily distributed datasets are expected to be the results of differential gene loss (or unequal rates of evolution). This would result in monophyletic eukaryotic sequences in the phylogenetic analyses. If, on the other hand, LGT is relatively common, eukaryotic sequences are expected to be polyphyletic. The analyses presented below indeed strongly suggest gene transfer to be an important evolutionary mechanism to spread patchily distributed genes between distantly related organisms, including eukaryotes.

\section{Methods}

The total set of 13,522 putative protein sequences encoded by the genome of the slime mold $D$. discoideum (http://dictybase. $\operatorname{org} /$ ) was used to search for protein families (clusters of proteins with primary sequence similarity) that showed patchy distribution. Figure 1 shows an overview of completed genome sequences included in the study. Putative protein sequences from TBestDB, a taxonomically broad database of expressed sequence tag (EST) data from 54 diverse lineages of microbial eukaryotes [O'Brien et al., 2007], were also included to increase the sampling of protist proteins in the study. This dataset has been carefully checked for potential contamination [O'Brien et al., 2007]. The inclusion of putative protein sequences from ESTs precluded the use of any method based on reciprocal best BLAST hits [Tatusov et al., 2000]. Therefore, the program package PhyloGenie [Frickey and Lupas, 2004] was used on the 9,952 of the $13,522 \mathrm{D}$. discoideum protein sequences longer than 200 amino acids. PhyloGenie automatically performs similarity searches against the collected databases, creates a Hidden Markov Model based on the matches that fulfill user-defined criteria, and uses this Hidden Markov Model to search a larger set of matches and finally produces an aligned dataset. See the original PhyloGenie publication for further details [Frickey and Lupas, 2004].

In this study, a protein family is defined as a group of sequences with detectable primary sequence similarity that is distinct from other such groups. A patchy distribution was defined as homologs being present in $D$. discoideum and at least one prokaryote, but not in more than 20 archaeal, 20 eukaryotic, or 60 bacterial species, for the purpose of this analysis. These numbers were 


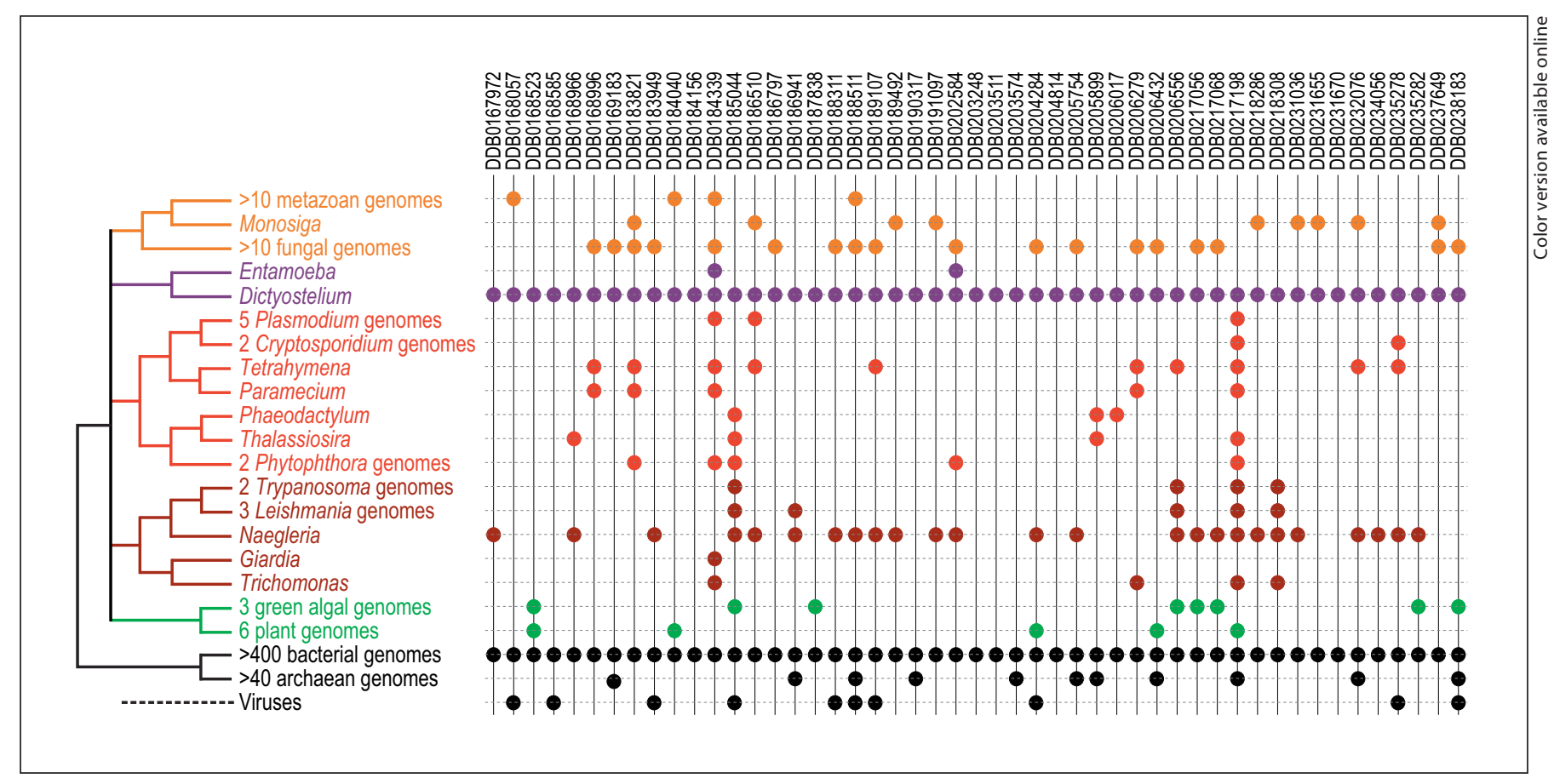

Fig. 1. Distribution of 49 genes present in Dictyostelium and prokaryotes among sequenced eukaryotic genomes. A schematic reference tree of completed genome sequences included in the study. Numbers indicate the number of genomes available from the taxonomic group. The topology is based on a current hypothesis for phylogenetic relationships of eukaryotes [Adl et al., 2005; Baldauf, 2003; Hampl et al., 2009], but see Parfrey et al. [2010]. Eukaryotes are labeled according to their classification into proposed super-

arbitrarily chosen to obtain a suitable number of datasets with a rather limited distribution among sequenced genomes. No criterion for the maximum number of paralogs within a species was applied. A setting where the maximum identity allowed for two sequences in the final dataset as $95 \%$ was used to avoid that many closely related sequences from species and genera overrepresented among genome projects are included in the dataset. Inspection of the result of the similarity searches revealed that these settings did not exclude any sequences with high similarity to Dictyostelium proteins which could represent a putatively very recent gene transfer event. Only datasets where the $D$. discoideum protein longer than 200 amino acids yielded a hit with an E-value better than $1 \mathrm{e}^{-20}$ to at least one non-Dictyostelium sequence in the initial similarity searches were considered for further analyses. This approach identified 94 proteins as patchily distributed, corresponding to 49 unique families (table 1). All alignments were inspected and a few misaligned and short sequences were removed (a total of 24 sequences in ten different datasets, corresponding to $1.7 \%$ of all sequences). The datasets are listed in table 1 and the alignments are available on request from the author.

The PhyloGenie package has been found to generate datasets with levels of sequence similarities suitable for phylogenetic reconstructions [Andersson et al., 2007; Frickey and Lupas, 2004; Hackett et al., 2007; Huang and Gogarten, 2007, 2008; Li et al., groups [Adl et al., 2005]: Amoebozoa (purple), Archaeplastida (green), Chromalveolata (red), Excavata (brown), and Opisthokonta (orange; colors refer to the online version). The presences of genes in individual genomes and taxonomic groups are shown with filled circles. A dot for a group indicates the presence in at least one of the genome sequences available. See table 1 for further characteristics of the datasets.

2006; Nosenko and Bhattacharya, 2007; Reyes-Prieto et al., 2006]. The 49 D. discoideum protein sequences were searched against the Pfam protein family database, version 23.0 [Finn et al., 2008] to test the consistency with another clustering method. Eight of the proteins had matches against Pfam families with $\mathrm{E}$ values better than $1 \mathrm{e}^{-55}$ (table 1). All these showed identical, or nearly identical (one species difference), phylogenetic distribution among eukaryotes as identified using PhyloGenie (fig. 1). An additional four $D$. discoideum proteins had Pfam matches with $\mathrm{E}$ values between $1 \mathrm{e}^{-55}$ and $1 \mathrm{e}^{-10}$ (table 1). These Pfams showed a wider phylogenetic distribution among eukaryotes than identified in this study. The boundary of the PhyloGenie clusters correlated with drastic drops in scores in the similarity searches, suggesting that the sequences represent sub-families distinct from the other sequences within the respective matching Pfam.

Automatically, maximum likelihood bootstrap analyses were performed on the 48 datasets with four or more sequences using phyml.pl. This is a PhyloGenie [Frickey and Lupas, 2004] script modified by Peter Cordes (Dalhousie University) which uses PHYML, version 2.4.4 [Guindon and Gascuel, 2003]. The WAG substitution matrix was used together with models for among site rate and invariable sites (WAG $+\mathrm{I}+\Gamma$ ) and a total of 100 bootstrap replicates were analyzed for each dataset. The codon usage and $\mathrm{G}+\mathrm{C}$ content of their genes were compared to the total set of 9,952 
Table 1. Summary of the 49 datasets with patchily distributed proteins

\begin{tabular}{|c|c|c|c|c|c|c|c|c|c|c|c|}
\hline \multirow[t]{2}{*}{ dictyBaseID } & \multirow[t]{2}{*}{ Figure } & \multirow{2}{*}{$\begin{array}{l}\text { Taxa, } \\
\text { No. }^{\text {a }}\end{array}$} & \multirow{2}{*}{$\begin{array}{l}\text { Pos., } \\
\text { No. }^{\text {b }}\end{array}$} & \multicolumn{2}{|c|}{ Eukaryotes } & \multicolumn{2}{|c|}{ D. discoideum } & \multirow[t]{2}{*}{ Gene product } & \multirow[t]{2}{*}{ GO biological process ${ }^{\mathrm{f}}$} & \multirow[t]{2}{*}{ Pfam $^{g}$} & \multirow{2}{*}{$\begin{array}{l}\text { E } \\
\text { values }^{2}\end{array}$} \\
\hline & & & & No. ${ }^{c}$ & Clan $^{\mathrm{d}}$ & No. ${ }^{\mathrm{e}}$ & Clan $^{\mathrm{d}}$ & & & & \\
\hline DDB0167972 & S1AA & 7 & 496 & 6 & ND & 5 & ++ & & & PF01841 & $1 e^{-21}$ \\
\hline DDB0168057 & S1AB & 85 & 211 & 3 & --- & 2 & +++ & $\begin{array}{l}\text { similar to fusolin } \\
\text { precursor and chitinases }\end{array}$ & - & PF03067 & $6 e^{-59}$ \\
\hline DDB0168523 & S1AC & 40 & 196 & 12 & -- & 1 & ND & & & PF09348 & $5 e^{-86}$ \\
\hline DDB0168585 & S1AD & 5 & 560 & 1 & ND & 1 & ND & $\begin{array}{l}\text { similar to amylovoran } \\
\text { biosynthesis protein } \\
\text { precursor }\end{array}$ & - & & \\
\hline DDB0168966 & S1AE & 11 & 208 & 6 & ++ & 1 & $\mathrm{ND}$ & & & & \\
\hline DDB0168996 & S1AF & 18 & 375 & 12 & ++ & 1 & ND & & & & \\
\hline DDB0169183 & S1AG & 65 & 157 & 5 & -- & 3 & +++ & $\begin{array}{l}\text { prespore-specific } \\
\text { protein }\end{array}$ & - & PF06555 & $2 \mathrm{e}^{-82}$ \\
\hline DDB0183821 & S1AH & 27 & 214 & 14 & --- & 1 & ND & & & & \\
\hline$\overline{\text { DDB0183949 }}$ & S1AI & 12 & 373 & 6 & -- & 1 & ND & & & PF09513 & $2 \mathrm{e}^{-204}$ \\
\hline DDB0184040 & S1AJ & 8 & 308 & 7 & ND & 2 & +++ & & & PF10354 & $6 e^{-45}$ \\
\hline DDB0184156 & S1AK & 34 & 302 & 3 & - & 3 & - & $\begin{array}{l}\text { similar to } \\
\text { acetyltransferases, } \\
\text { GNAT family }\end{array}$ & metabolic process & & \\
\hline DDB0184339 & S1AL & 78 & 375 & 75 & - & 8 & --- & & & & \\
\hline DDB0185044 & S1AM & 64 & 248 & 46 & -- & 2 & -- & GlcNAc transferase ${ }^{h}$ & $\begin{array}{l}\text { protein amino acid } \\
\text { glycosylation }\end{array}$ & & \\
\hline DDB0186510 & S1AN & 24 & 208 & 23 & ND & 2 & +++ & & & & \\
\hline DDB0186797 & $\mathrm{S} 1 \mathrm{AO}$ & 33 & 348 & 7 & --- & 2 & +++ & $\begin{array}{l}\text { similar to glycoside } \\
\text { hydrolases }\end{array}$ & $\begin{array}{l}\text { carbohydrate metabolic } \\
\text { process }\end{array}$ & & \\
\hline DDB0186941 & S1AP, 2D & 11 & 220 & 4 & -- & 1 & $\mathrm{ND}$ & & & & \\
\hline DDB0187838 & S1AQ & 25 & 561 & 6 & -- & 5 & +++ & & & PF10462 & $3 e^{-173}$ \\
\hline$\overline{\mathrm{DDB} 0188311}$ & S1AR & 37 & 365 & 16 & -- & 2 & +++ & & & PF09511 & $2 \mathrm{e}^{-134}$ \\
\hline$\overline{\text { DDB0188511 }}$ & S1AS & 78 & 364 & 41 & -- & 1 & ND & ADP-ribosylhydrolase & $\begin{array}{l}\text { protein amino acid } \\
\text { ADP-ribosylation }\end{array}$ & PF03747 & $1 \mathrm{e}^{-52}$ \\
\hline DDB0189107 & S1AT & 46 & 278 & 39 & -- & 10 & + & & & & \\
\hline DDB0189492 & S1AU & 61 & 207 & 8 & - & 1 & $\mathrm{ND}$ & & & PF08857 & $3 e^{-96}$ \\
\hline DDB0190317 & $\mathrm{S} 1 \mathrm{AV}, 2 \mathrm{~A}$ & 38 & 350 & 1 & ND & 1 & ND & $\begin{array}{l}\text { aminoglycoside } \\
\text { phosphotransferase }\end{array}$ & response to antibiotic & & \\
\hline DDB0191097 & S1AW, 2C & 8 & 672 & 5 & +++ & 1 & ND & $\begin{array}{l}\text { conditioned medium } \\
\text { factor }^{\mathrm{h}}\end{array}$ & & & \\
\hline DDB0202584 & S1AX & 47 & 264 & 22 & --- & 2 & +++ & similar to esterases & - & & \\
\hline DDB0203248 & S1AY & 11 & 262 & 1 & ND & 1 & $\mathrm{ND}$ & & & & \\
\hline DDB0203511 & - & 2 & 458 & 1 & ND & 1 & ND & & & & \\
\hline DDB0203574 & S1AZ & 47 & 206 & 1 & ND & 1 & $\mathrm{ND}$ & & & & \\
\hline DDB0204284 & S1BA & 33 & 378 & 26 & -- & 1 & $\mathrm{ND}$ & & & & \\
\hline DDB0204814 & S1BB & 63 & 305 & 1 & ND & 1 & $\mathrm{ND}$ & $\begin{array}{l}\text { galactose-1-phosphate } \\
\text { uridylyltransferase }\end{array}$ & $\begin{array}{l}\text { galactose metabolic } \\
\text { process }\end{array}$ & & \\
\hline DDB0205754 & S1BC & 46 & 294 & 7 & -- & 1 & ND & & & & \\
\hline DDB0205899 & S1BD & 40 & 644 & 13 & --- & 5 & --- & & & & \\
\hline DDB0206017 & S1BE & 51 & 494 & 7 & --- & 2 & +++ & similar to permeases & transport & & \\
\hline DDB0206279 & S1BF, 2F & 58 & 370 & 8 & --- & 2 & --- & & & & \\
\hline$\overline{\text { DDB0206432 }}$ & S1BG & 44 & 431 & 19 & --- & 1 & ND & $\begin{array}{l}\text { similar to } \\
\text { amidohydrolases }\end{array}$ & metabolic process & PF04909 & $1 \mathrm{e}^{-15}$ \\
\hline DDB0206556 & S1BH & 76 & 315 & 20 & -- & 2 & - & $\begin{array}{l}\text { similar to } \\
\text { amidinotransferases }\end{array}$ & metabolic process & & \\
\hline$\underline{\text { DDB0217056 }}$ & S1BI, 2E & 29 & 357 & 16 & ++ & 2 & -- & & & & \\
\hline DDB0217068 & S1BJ & 76 & 173 & 71 & -- & 5 & -- & & & & \\
\hline
\end{tabular}


Table 1 (continued)

\begin{tabular}{|c|c|c|c|c|c|c|c|c|c|c|c|}
\hline \multirow[t]{2}{*}{ dictyBaseID } & \multirow[t]{2}{*}{ Figure } & \multirow{2}{*}{$\begin{array}{l}\text { Taxa, } \\
\text { No. }^{a}\end{array}$} & \multirow{2}{*}{$\begin{array}{l}\text { Pos., } \\
\text { No. }\end{array}$} & \multicolumn{2}{|c|}{ Eukaryotes } & \multicolumn{2}{|c|}{ D. discoideum } & \multirow[t]{2}{*}{ Gene product } & \multirow[t]{2}{*}{ GO biological process ${ }^{f}$} & \multirow[t]{2}{*}{ Pfam $^{g}$} & \multirow{2}{*}{$\begin{array}{l}\text { E } \\
\text { value }^{8}\end{array}$} \\
\hline & & & & No. ${ }^{c}$ & Clan $^{\mathrm{d}}$ & $\mathrm{No}^{\mathrm{e}}$ & Clan $^{\mathrm{d}}$ & & & & \\
\hline DDB0217198 & S1BK & 59 & 193 & 29 & - & 2 & --- & $\begin{array}{l}\text { similar to 2-phospho- } \\
\text { glycerate kinase }\end{array}$ & - & & \\
\hline DDB0218286 & S1BL & 99 & 324 & 8 & -- & 2 & ++ & $\begin{array}{l}\text { similar to glycosyl } \\
\text { hydrolase }\end{array}$ & $\begin{array}{l}\text { carbohydrate metabolic } \\
\text { process }\end{array}$ & & \\
\hline DDB0218308 & S1BM & 49 & 336 & 24 & +++ & 1 & ND & similar to glucokinase & glycolysis & & \\
\hline DDB0231036 & S1BN & 56 & 422 & 27 & -- & 5 & ++ & AprA $^{\text {h }}$ & $\begin{array}{l}\text { regulation of aggregate } \\
\text { size; negative regulation } \\
\text { of cell proliferation; } \\
\text { sporulation }\end{array}$ & PF10142 & $9 \mathrm{e}^{-258}$ \\
\hline DDB0231655 & S1BO & 142 & 153 & 122 & --- & 108 & --- & $\begin{array}{l}\text { large family containing } \\
\text { prespore cell-inducing } \\
\text { factor, extracellular } \\
\text { matrix proteins, etc. }\end{array}$ & - & & \\
\hline DDB0231670 & S1BP & 5 & 377 & 3 & +++ & 3 & +++ & & & & \\
\hline DDB0232076 & S1BQ & 38 & 181 & 29 & - & 4 & --- & $\begin{array}{l}\text { similar to } \mathrm{N} \text {-acylsphin- } \\
\text { gosine amidohydrolase }\end{array}$ & - & & \\
\hline DDB0234056 & S1BR & 6 & 544 & 5 & ND & 3 & +++ & vacuolin $^{\mathrm{h}}$ & & & \\
\hline DDB0235278 & S1BS, 2B & 72 & 270 & 15 & -- & 2 & +++ & similar to patatins & lipid metabolic process & & \\
\hline DDB0235282 & S1BT & 46 & 711 & 4 & - & 1 & ND & similar to patatins & lipid metabolic process & & \\
\hline DDB0237649 & S1BU & 20 & 300 & 18 & -- & 3 & --- & & & & \\
\hline DDB0238183 & S1BV & 50 & 252 & 6 & --- & 2 & - & similar to chitinases & $\begin{array}{l}\text { carbohydrate metabolic } \\
\text { process }\end{array}$ & & \\
\hline
\end{tabular}

\begin{abstract}
a Total number of taxa included in the dataset. ${ }^{b}$ Number of positions in the Dictyostelium protein used in the phylogenetic analyses. ${ }^{c}$ Total number of eukaryotic sequences. ${ }^{\mathrm{d}}+++,++$, and + indicate whether the sequences formed a clan [Wilkinson et al., 2007] with $\geq 95, \geq 50,<50 \%$ bootstrap support, respectively (monophyly). ---, --, and - indicate that the sequences are split into two or more clans with sequences from other domains with $\geq 95, \geq 50,<50 \%$ bootstrap support, respectively (polyphyly). ND indi-

genes coding for proteins longer than 200 amino acids analyzed using the program CodonW (http://codonw.sourceforge.net/).

Potential functions for the proteins were retrieved by searching dictyBase by all $D$. discoideum proteins included in the 49 datasets. References to functional characterizations were found for proteins from four of the datasets. Putative gene functions for the remaining protein families were retrieved either from dictyBase in combination with similarity searches against the non-redundant database. Biological processes Gene Ontology terms [Ashburner et al., 2000] of the protein families were retrieved from dictyBase or the Gene Ontology web page (http://www.geneontology.org/).
\end{abstract}

cates that monophyly cannot be tested since only a single sequence from the group, or a single sequence from outside the group is present. ${ }^{\mathrm{e}}$ Number of $D$. discoideum sequences. ${ }^{\mathrm{f}}$ Biological processes Gene Ontology terms [Ashburner et al., 2000]. ' Results of Pfam searches [Finn et al., 2008]. ${ }^{\mathrm{h}}$ These gene products have been functionally characterized (see main text for details).

\section{Results and Discussion}

The screening procedure identified 49 patchily distributed proteins shared between the slime mold $D$. discoideum and at least one prokaryote present in the databases. Two complementary evolutionary analyses were performed on these protein families. Firstly, the phylogenetic distributions were compared to the expected organismal relationships between the genomes included in the study. Secondly, the phylogenetic relationships within the protein families were studied.

\section{Unexpected Phylogenetic Distribution of the 49 \\ Protein Families}

The compositions within the 49 datasets vary greatly; the total number of taxa is between 2 and 142, and the number of $D$. discoideum paralogs varies between 1 and 108 (table 1). The occurrences of other taxa in the dataset were analyzed using the PHATG program within PhyloGenie [Frickey and Lupas, 2004] in order to study patterns of phylogenetic distribution among patchily distributed $D$. discoideum genes (fig. 1 and online suppl. table 1; for all online supplementary material, see www. karger.com/doi/10.1159/000324505). Entamoeba histolyt- 
ica is the only other completely sequenced member of Amoebozoa (fig. 1). Interestingly, this amoeba is present in only two of the 49 datasets (online suppl. table 1), indicative of loss of genes in the lineages leading to the human parasite E. histolytica, or gain in the lineage leading to Dictyostelium. Furthermore, the genus Naegleria, represented by the draft genome of Naegleria gruberi, an aerobic amoeboflagellate classified within Excavata [Adl et al., 2005], is present in half of the datasets (fig. 1), while the parasite Leishmania major is represented only in five (fig. 1). No additional homologs were found when the 49 patchily distributed $D$. discoideum proteins were used in similarity searches against their translated nucleotide Entamoeba and Leishmania genome sequences, indicating that the differences are not due to erroneous annotations of nucleotide sequences. However, they may reflect gene losses in the lineages leading to the parasites. The pattern could also be produced by lineage variations in evolutionary rates that lead to problems in identifying members of the protein families in some branches of the tree. In both cases the identified eukaryotes are expected to form a distinct (monophyletic) group to the exclusion of all other sequences in a phylogenetic analysis.

\section{Phylogenetic Analyses Indicate Inter- and}

Intra-Domain LGT in Patchily Distributed Proteins

Maximum likelihood analyses were performed for the datasets in order to gain more insights into the evolution of the individual genes. The phylogenetic trees show complex topologies often at odds with organismal relationships. The complex topologies are likely the results of gene duplications, losses, LGT and perhaps endosymbiotic gene transfers in the evolution of the patchily distributed proteins. All trees are found in online supplementary figure 1, and six trees representing the diversity of topologies obtained are shown in figure 2 . Inferences based on alignments of single genes may be prone to artifacts due to the use of suboptimal models of the sequence evolution in the analyses and a limited number of sites in the alignments. However, it is unlikely that phylogenetic artifacts could have produced the anomalous topologies on a large scale. Many trees show sequences from distantly related organisms clustering tightly together (fig. 2 and online suppl. fig. 1), which is very difficult to explain solely by methodological artifacts.

Thirty-nine of the datasets contain multiple eukaryotic and multiple non-eukaryotic sequences (table 1). The topology of these were analyzed for the presence or absence of eukaryotic clans (the term 'clade' is problematic for these unrooted phylogenies [Wilkinson et al., 2007]).
A single clan is expected if only vertical inheritance has occurred, while inter-domain gene transfers could have created a larger number of clans. At any rate, in most trees (33 of 39) the eukaryotic sequences are found in two or more clans, ten of which with $>95 \%$ support for the association of eukaryotic and non-eukaryotic sequences (fig. 2b, d, f; table 1). This indicates that LGT is likely to have affected the evolution of these patchily distributed proteins identified in Dictyostelium. An alternative explanation for the occurrence of multiple eukaryotic clans could be that paralogs of the gene were present in the last universal common ancestor. If these were differentially lost in eukaryotes they could create topologies falsely interpreted as being the result of gene transfer. However, such a scenario would often require maintenance of paralogs in many lineages for long evolutionary time scales followed by recent independent losses. It would also require the presence of multiple copies in ancestral organisms. In many cases, the eukaryotic clans containing one or a few eukaryotic species group with bacterial or archaeal sequences with rather strong statistical support (fig. 2d, f). This strongly favors inter-domain gene transfer scenarios, since it requires a large number of recent gene losses in the absence of gene transfer. Together with the analyses of phylogenetic distribution (fig. 1), the phylogenetic analyses strongly suggest that LGT has affected the majority of the identified patchily distributed protein families to some extent. However, the evolutionary events cannot be reconstructed in detail for most of the families due to methodological limitations and incomplete sampling [see Andersson, 2009b, for further discussion].

The evolutionary histories for the six families showing a single eukaryotic clan are more difficult to interpret (table 1). Interestingly, all five of those that contain multiple eukaryotic species (the sixth contains three $D$. discoideum

Fig. 2. Phylogenetic trees of six patchily distributed $D$. discoideum proteins. Maximum likelihood trees of conceptually translated aligned amino acid positions of aminoglycoside phosphotransferase (a), a protein with similarity to patatins (b), conditioned medium factor (c), and conserved hypothetical proteins (d-f) (datasets DDB0186941, DDB0217056 and DDB0206279, respectively). Bootstrap support values $>50 \%$ are shown. Accession numbers are found in online supplementary figure 1 . The unrooted trees are arbitrarily rooted for the presentation. Archaeal, bacterial and viral names are labeled red, black and light blue, respectively. Eukaryotes are in bold and labeled according to their classification into super-groups [Adl et al., 2005]: Amoebozoa (purple), Archaeplastida (green), Chromalveolata (red), Excavata (brown), Opisthokonta (orange), and Rhizaria (dark blue; colors refer to the online version). 


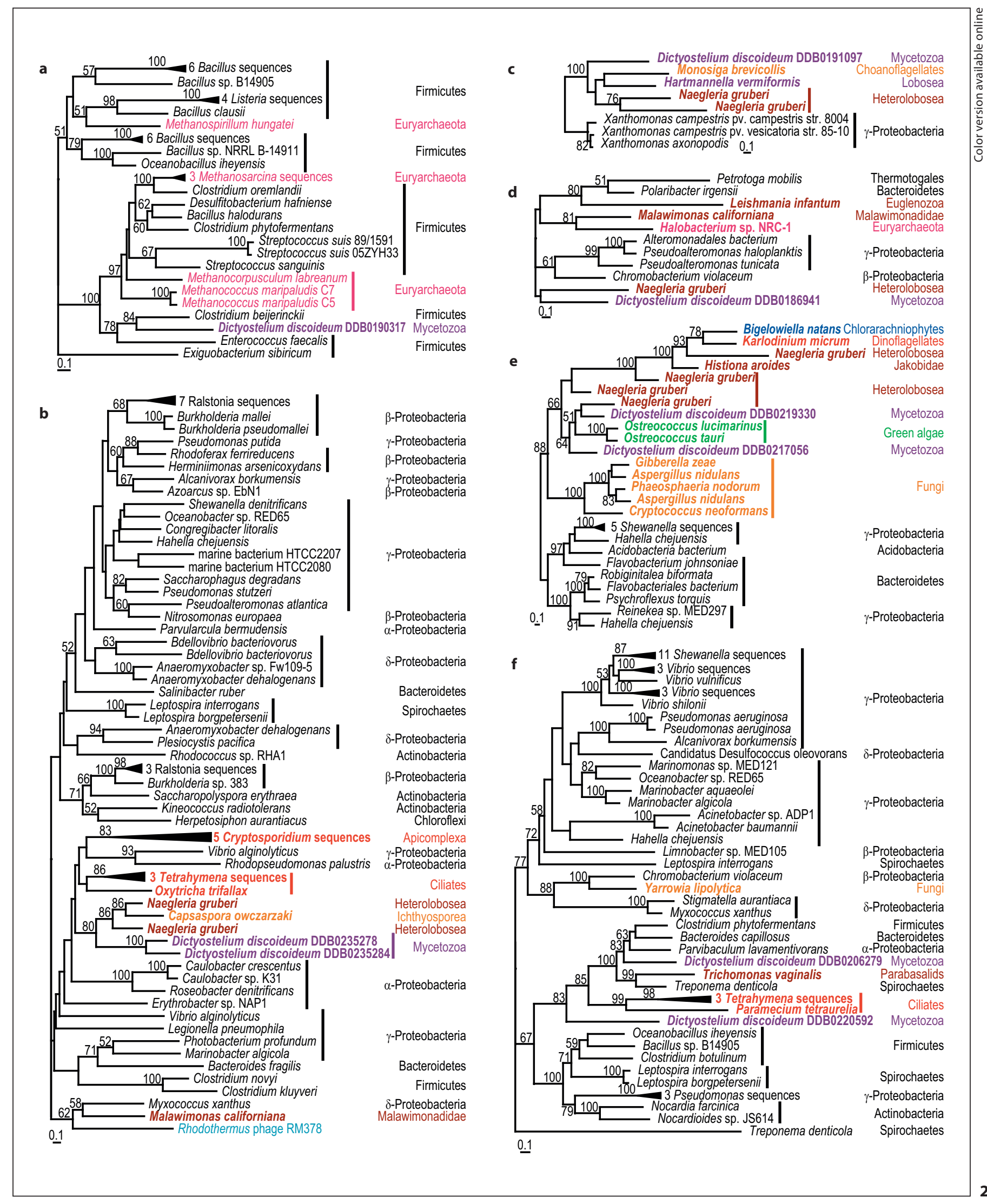


paralogs) fail to reproduce the expected organismal relationships within the eukaryotic clan (fig. $2 c$, e, online suppl. fig. 1AE, AF and BM). This could indicate a spread of the gene in eukaryotes via intra-domain gene transfer rather than vertical inheritance since the last common eukaryotic ancestor. However, vertical inheritance followed by differential loss is also a plausible explanation; additional sampling of diverse eukaryotes is needed to further test how these proteins have been distributed.

\section{Unexpected Groupings of Eukaryotes Suggest}

\section{Additional Transfers}

The phylogenies of many of the patchily distributed proteins show clans containing distantly related eukaryotes (fig. $2 b-e$ ). Such unexpected grouping of protists could either be explained by an inter-domain LGT followed by an intra-domain transfer or by multiple independent interdomain transfers from not-yet-sampled or extinct prokaryotic lineages [Andersson, 2009a; Keeling and Palmer, 2008]. For example, the close relationships between the Capsaspora and Naegleria sequences in the tree of patatinlike proteins (fig. 2b) and between Karlodinium, Bigelowiella and Naegleria sequences in figure 2e possibly represent intra-eukaryotic gene transfers. The grouping of the Naegleria and Dictyostelium sequences in figure $2 \mathrm{~d}$, on the other hand, could very well be the result of two independent prokaryote-to-eukaryote gene transfers. Further taxon sampling is obviously needed to resolve the patterns of putative transfers, and/or gene losses, for each individual protein family. Nevertheless, these topologies are part of an emerging trend; many similar topologies have recently been found in phylogenetic studies of protist genes of prokaryotic origin [Andersson, 2009a; Andersson et al., 2006, 2007; Hampl et al., 2008; Keeling and Palmer, 2008; Nosenko and Bhattacharya, 2007; Richards et al., 2006; Rogers et al., 2007; Stechmann et al., 2006]. They are usually interpreted as sequential transfers between eukaryotes, after an initial transfer from a prokaryote. This could possibly be rationalized by a higher probability for a foreign eukaryotic gene to be functional once incorporated into the eukaryotic nucleus because of the differences in transcription and translational machineries between the domains of life [Andersson, 2009a]. Although these are interesting observations, studies targeting this particular aspect of gene transfer are needed to get a better understanding.

\section{Directions and Timing of Transfers for Patchily}

Distributed Genes

The direction of a gene transfer event can only be determined beyond any reasonable doubt if the recipient lineage is nested within a clade of donor lineages that show the expected organismal phylogeny. Such identification requires that the transfer is an exception in the evolution of the protein family in question. This seldom seems to be the case for patchily distributed proteins at the current depth of sampling of organismal diversity. Accordingly, it cannot be excluded that some of the putative transfers have been from endosymbionts (e.g. mitochondria or chloroplasts) to the nucleus of the host lineage, although the sources and directions of most of the putative transfers in these datasets are elusive. A much denser taxon sampling is needed in order to determine donor and recipient lineages for individual transfers [Andersson, 2009b].

An alternative approach to determine the direction and timing of a gene transfer event takes advantage of the observation that genomes of distantly related organisms have different properties. For example, a gene $\mathrm{G}+\mathrm{C}$ content that differs significantly from the majority of the genes in the genome could be hypothesized to have been recently introduced into the genome [Lawrence and Ochman, 1997; Ragan, 2001]. No indications of recent acquisitions of any of the 49 patchily distributed genes were found using this approach. Similarly, neither correspondence analysis of the relative synonymous codon usage, nor analysis of intron density identified any obvious differences between the patchily distributed genes and the total set of $D$. discoideum genes (online suppl. table 2 and online suppl. fig. 2). These observations probably indicate that the majority of the patchily distributed genes have been present in the Dictyostelium lineage long enough to have ameliorated to its genomic characteristics. In fact, 47 of the 49 proteins do have orthologs in the Dictyostelium purpureum genome data made available at the US Department of Energy Joint Genome Institute (http:// www.jgi.doe.gov/) after the analyses were completed.

\section{Proteins Involved in Cellular Functions Shared between Distantly Related Microbes}

Potential functions for the proteins were retrieved from dictyBase and by similarity searches against the non-redundant (nr) database at NCBI (table 1). Four of the 49 protein families have members with characterized functions in $D$. discoideum and five proteins have strong similarities to characterized proteins from other organisms. Another $15 \mathrm{D}$. discoideum gene products could be assigned a putative function based on weak similarities. 25 of the 49 genes encode conserved hypothetical proteins with unknown function. Roles in metabolic processes dominate among the genes that do have assigned 
putative functions (table 1). Over-representation of metabolic genes is usually observed in phylogenomic studies of eukaryotic LGT, which has been rationalized by metabolic adaptation in the recipient eukaryotic lineage [Andersson et al., 2007; Bowler et al., 2008; Carlton et al., 2007; Loftus et al., 2005; Ricard et al., 2006]. Interestingly, functions in protein glycosylation, cell communication, and regulation of cell development also are present among the patchily distributed genes (table 1).

Two of the four proteins that have been functionally characterized in $D$. discoideum encode secreted proteins involved in regulation of cell development (table 1). The conditioned medium factor is an $80-\mathrm{kDa}$ glycoprotein secreted by starved cells that is required for aggregation [Jain et al., 1992], and the autocrine proliferation repressor (AprA) inhibits cell proliferation [Brock and Gomer, 2005]. Although the conditioned medium factor was identified more than a decade ago, no homologs have been known; genes with sequence similarities were only recently described in bacterial phytopathogens of the genus Xanthomonas [Andrade et al., 2006]. Similarly, homologous genes coding for AprA have only been found in Dictyostelium and a few bacterial species [Brock and Gomer, 2005]. Fascinatingly, both these genes are now detected in the amoeboflagellate N. gruberi [Fritz-Laylin et al., 2010] and the choanoflagellate Monosiga brevicollis [King et al., 2008], as well as in the EST dataset from the tubulinean Hartmanella vermiformis (online suppl. fig. $1 \mathrm{AW}$ and $\mathrm{BN}$ ). In addition, AprA homologs were detected in the excavates Malawimonas californiana, Malawimonas jakobifromis, Jakoba libera and Histiona aroides, the chlorarachniophyte Bigelowiella natans, and a number of bacterial lineages (online suppl. fig. 1BN). This indicates that these secreted cell communication proteins have a broader phylogenetic distribution than previously appreciated, suggesting similarities in cell development between distantly related microbes.

Skp1 is a protein found in several eukaryotic protein complexes [West, 2003]. It is glycosylated by UDP-N-actetylglucosamine(GlcNAc):hydroxyproline Skp1 GlcNAc transferase. In $D$. discoideum, this reaction is performed in the cytosol, whereas in animal cells the glycosylation is performed in the Golgi apparatus by distantly related enzymes [West, 2003]. The Dictyostelium sequence was initially found to be most similar to bacterial sequences [Van Der Wel et al., 2002]. Here, it is shown that a large part of the eukaryotic diversity actually encodes the Dictyostelium type of the enzyme (online suppl. fig. 1AM). The fourth gene with a functionally characterized gene product codes for vacuolin. This protein targets the vacu- ole for exocytosis, and characterizes the post-lysosomal compartment [Brock and Gomer, 2005]. No homologs have previously been detected, but in this analysis two are found in amoeboflagellate N. gruberi, and another in the $\gamma$-proteobacteria Coxiella burnetii, strain Dugway 7E912 (online suppl. fig. 1BR). Intriguingly, C. burnetii - the etiological agent of $\mathrm{Q}$ fever - is highly adapted to a life in acidic eukaryotic phagolysosomes [Seshadri et al., 2003], and expression of a vacuolin might be a mechanism for host modulation.

\section{Analyses of Gene Transfers Are Heavily Dependent on} Experimental Approaches

The original analysis of the $D$. discoideum genome sequence identified 18 potential gene transfers [Eichinger et al., 2005]. The criterion used to classify a gene as a putative transfer was that the $D$. discoideum protein domain matched a bacteria-specific Pfam domain and had phylogenetic relationships indicative of LGT [Eichinger et al., 2005]. Consequently, only datasets where $D$. discoideum is the only eukaryote, such as in figure $2 \mathrm{a}$, were considered. All proteins that have homologs in other eukaryotic genomes were excluded. This study suggests a conservative approach to find gene families that have participated in gene transfer events because the vast majority of the patchily distributed proteins do have eukaryotic homologs outside Amoebozoa, yet most have likely been transferred relatively recently (fig. 2b-f). Only one of the 18 previously identified putative gene transfers [Eichinger et al., 2005] is included among the 49 datasets of patchily distributed proteins identified in this analysis (a pre-spore specific protein). This is a reflection of the different approaches; the number of genes affected by LGT in the D. discoideum genome is likely much larger than the sum of the candidate genes in the two analyses. Likewise, the 191 gene transfer candidates reported from the genome of the amoeboflagellate N. gruberi are very likely only the tip of the iceberg of LGTs affecting this heterolobosean lineage; only genes with homologies in prokaryotes, but no other eukaryotic group, were considered [Fritz-Laylin et al., 2010].

Interestingly, this study includes 14 phylogenetic trees where $D$. discoideum sequences are found in multiple clans, seven of which with bootstrap support values above $95 \%$ for their separation (fig. 2e, f; table 1). For several of these, the most likely explanation is that the slime mold has acquired genes coding for homologous proteins repeatedly from different sources, sometimes followed by gene duplications within the lineage (i.e. fig. $2 \mathrm{f}$, online suppl. fig. $1 \mathrm{BD}$ and $1 \mathrm{BF}$ ). Thus, LGT has contributed to 
gene family expansions, at least to some extent, in the Dictyostelium genome, as has been suggested for prokaryotes [Lerat et al., 2005].

There are no indications that the patchily distributed proteins were acquired in a single or a few events; they are found on all six D. discoideum chromosomes and are not clustered, no specific donor lineage among the genes could be identified, and there are no indications that they are functionally related. This suggests that genes have been from various sources over evolutionary time in the lineage leading to Dictyostelium. A much denser taxon sampling would be needed to determine the rate of this process. However, the facts that the gene sequences have ameliorated to the $D$. discoideum genome (see above) and that $96 \%$ of the gene families are present in D. purpureum indicate that the process is considerably slower than observed in some bacterial genera [Kettler et al., 2007; Welch et al., 2002]. Interestingly, a recent comparison of three sequenced isolates of the human intestinal parasite Giardia intestinalis species complex also indicated ongoing gene acquisitions. Dozens of lineage-specific genes were identified, some of which clearly have very recent origins from bacteria inhabiting the intestine [Franzén et al., 2009; Jerlström-Hultqvist et al., 2010].

\section{Co-Occurrence of Proteins in Organisms within}

Similar Environments

The phylogenetic distributions of the datasets were analyzed on the genus level (fig. 1 and online suppl. table 1). By far the most represented genus is Naegleria (heterolobosea), amoeboflagellates found in soil and fresh water [De Jonckheere, 2002; Fritz-Laylin et al., 2010], which is present in 25 of the 49 datasets. Naegleria and Dictyostelium belong to different super-groups, Excavata and Amoebozoa, respectively (fig. 1). This strongly suggests that the co-occurrence of genes in Dictyostelium and Naegleria is not explained by a recent common ancestry of the two eukaryotes. A more reasonable explanation for this observation is that they have similar lifestyles and therefore share these genes which probably were acquired via gene transfers; the habitats of both genera include soil and they have amoeboid life stages where they feed on bacteria. Interestingly, fungi, another group with many soil organisms, are also frequently represented within these 49 datasets (fig. 1).

In general, free-living heterotrophic aerobic microbial eukaryotic groups (i.e. Monosiga, fungi, Dictyostelium, ciliates, Naegleria) are more frequently found among the datasets than parasites (i.e. Entamoeba), autotrophs (i.e. Phaeodactylum), and multicellular eukaryotes (fig. 1).
This is unlikely only due to large differences in rates of gene transfers between eukaryotes because both Entamoeba and Phaeodactylum have been reported to have acquired a substantial number of bacterial genes [Bowler et al., 2008; Loftus et al., 2005]. Similarly, the ten bacterial genera represented in seven or more datasets are all mesophilic heterotrophs (online suppl. table 1), many of which have free-living members that are frequently found in soil (i.e. Burkholderia, Bacillus, Mycobacterium, Myxococcus, Stigmatella and Streptomyces - online suppl. table 1). Interestingly, $9.2 \%$ of the top-ten hits in similarity searches against the environmental sample database at the National Center for Biotechnology Information (http://www.ncbi.nlm.nih.gov/) are from a Minnesota farm soil dataset [Tringe et al., 2005], which represent $2.5 \%$ of the database. These observations are in agreement with a scenario where these genes tend to be shared within a soil environment.

This kind of co-occurrence of proteins in organisms found in similar environments has been observed in prokaryotes, which has been suggested to be important in the diversification process [Beiko et al., 2005; Boucher et al., 2003]. More recent data have appeared indicating that microbial eukaryote may adapt via gene acquisitions from prokaryotes [Andersson, 2009a; Keeling, 2009]. For example, protists have adapted to anaerobic lifestyle via gene acquisitions from anaerobic prokaryotes [Andersson et al., 2007; Carlton et al., 2007; Loftus et al., 2005; Ricard et al., 2006], and uptake of bacterial genes has likely led to early diversification of plants [Huang and Gogarten, 2008]. Such gene sharing may also happen between microbial eukaryotes; plant pathogens belonging to the distantly related groups oomycetes and fungi have exchanged a dozen genes which are related to their similar lifestyles [Richards et al., 2006]. Gene exchanges may indeed lead to direct changes of the phenotype of the recipient [Andersson, 2009a]. For example, transfer of virulence factors between different lineages of fungi has led to emergences of new plant pathogens within historical time [Friesen et al., 2006; Temporini and VanEtten, 2004]. The results presented in this study indicate that gene exchange occurs between soil organisms from all domains. These gene transfer events have most likely changed the phenotypes of the recipients, although the impact of every single gene is impossible to determine.

\section{Patchily Distributed Genes Have Been Shared by a Variety of Mechanisms}

Many of the most common eukaryotes in the datasets are phagotrophs both on prokaryotic and eukaryotic cells 
(e.g. Naegleria and Dictyostelium). This mode of feeding has been suggested to be a mechanism by which DNA are introduced into the eukaryotic cell [Doolittle, 1998]. However, there are also a number of fungi (non-phagotrophs) present in the datasets (fig. 1 and online suppl. fig. 1, and online suppl. table 1). In many cases the fungal sequences group with prokaryotic sequences (fig. $2 \mathrm{f}$ and online suppl. fig. 1), strongly indicating that they have participated in inter-domain transfers. This indicates that there are additional mechanisms besides phagotrophy by which foreign genetic material may enter the eukaryotic cell. Interestingly, viral sequences were present in ten of the datasets (online suppl. fig. 1) hinting at transduction as a mechanism. Eukaryotic viruses may indeed harbor a large fraction of prokaryotic-like genes [Filée et al., 2007; Moreira and Brochier-Armanet, 2008]. Intriguingly, Mimivirus also harbors genes closely related to eukaryotic lineages such as Dictyostelium and Heterolobosea [Moreira and Brochier-Armanet, 2008]. These observations hint at a role for viruses both in inter- and intra-domain gene transfer.

\section{Concluding Remarks}

The case study presented here suggests that proteins shared between Dictyostelium and bacteria, but only a minority of other taxa available in the databases, belong to protein families which undergo frequent gene transfer. This has most likely contributed significantly to the adaptation process of this model eukaryote. The filter criteria used in this study were developed to avoid false positives and to get a suitable number of datasets. Less strict cut-offs would have included additional families, whereas more strict cut-offs would have resulted in a subset of the families. There does not seem to be any strong correlation between unexpected topologies and the size of the datasets. Both small and large datasets show anomalous topologies (fig. 2 and online suppl. fig. 1, table 1). Using different filtering criteria would include a slightly larger or slightly smaller number of protein families. For example, allowing half the number of species reduces the number of datasets to 21 (online suppl. fig. 1). Taken together, this indicates that the general patterns observed are not critically dependent on the selection criteria, although the details would change with different settings. Future similar studies would need to optimize their own selection criteria based on the specific question asked and the expected phylogenetic and environmental biases among the genomes available in the public databases.
Interestingly, the number of genes in this study is slightly higher than the 36 orthologs found suitable to reconstruct the universal tree of life [Ciccarelli et al., 2006], later coined as 'the tree of one percent' [Dagan and Martin, 2006]. 31 of the 36 identified universal gene families were reported to likely have been distributed via vertical descent in the three domains of life throughout evolutionary time [Ciccarelli et al., 2006]. Thus, the rate of LGT is extremely different for the universally conserved proteins compared to the patchily distributed proteins in this study. It is impossible to predict the relative contribution of vertical descent, gene loss and gene transfer for the remaining $>98 \%$ of the proteins in microbial eukaryotes in the absence of systematic studies.

Nevertheless, genomes of microbial eukaryotes contain a subset of genes that are exchangeable over evolutionary time, as has been observed in prokaryotes [Abby and Daubin, 2007; Lapierre and Gogarten, 2009]. The size and turnover rates of this subset of eukaryotic genes remain to be determined for various lineages and evolutionary time scales. Functional characterizations of the genes identified in this case study are expected to provide further insights into the biology of $D$. discoideum. Intriguingly, the proteins with the least widespread distributions are expected to provide most to the characteristic phenotype of any organism. Additional studies of the function and evolution of patchily distributed proteins will deepen the understanding of the diversification process of microbes from all domains of life.

\section{Acknowledgements}

The availability of preliminary sequences from the US Department of Energy Joint Genome Institute is greatly acknowledged. This work was supported by the Swedish Research Council (VR).

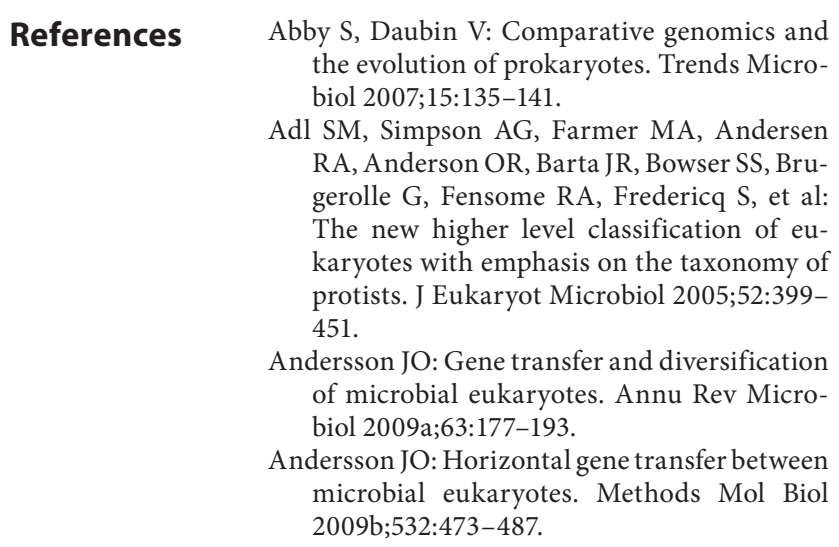

J Mol Microbiol Biotechnol 2011;20:83-95 93 
Andersson JO, Hirt RP, Foster PG, Roger AJ: Evolution of four gene families with patchy phylogenetic distribution: influx of genes into protist genomes. BMC Evol Biol 2006;6: 27.

-Andersson JO, Sjögren ÅM, Davis LAM, Embley TM, Roger AJ: Phylogenetic analyses of diplomonad genes reveal frequent lateral gene transfers affecting eukaryotes. Curr Biol 2003;13:94-104.

-Andersson JO, Sjögren ÅM, Horner DS, Murphy CA, Dyal PL, Svärd SG, Logsdon JM Jr, Ragan MA, Hirt RP, Roger AJ: A genomic survey of the fish parasite Spironucleus salmonicida indicates genomic plasticity among diplomonads and significant lateral gene transfer in eukaryote genome evolution. BMC Genomics 2007;8:51.

-Andrade MO, Alegria MC, Guzzo CR, Docena C, Rosa MC, Ramos CH, Farah CS: The HDGYP domain of RpfG mediates a direct linkage between the Rpf quorum-sensing pathway and a subset of diguanylate cyclase proteins in the phytopathogen Xanthomonas axonopodis pv citri. Mol Microbiol 2006;62: 537-551.

-Archibald JM, Rogers MB, Toop M, Ishida K, Keeling PJ: Lateral gene transfer and the evolution of plastid-targeted proteins in the secondary plastid-containing alga Bigelowiella natans. Proc Natl Acad Sci USA 2003;100: 7678-7683.

-Ashburner M, Ball CA, Blake JA, Botstein D, Butler H, Cherry JM, Davis AP, Dolinski K, Dwight SS, Eppig JT, et al: Gene ontology: tool for the unification of biology. The Gene Ontology Consortium. Nat Genet 2000;25: 25-29.

Baldauf SL: The deep roots of eukaryotes. Science 2003;300:1703-1706.

Bapteste E, O’Malley MA, Beiko RG, Ereshefsky M, Gogarten JP, Franklin-Hall L, Lapointe FJ, Dupre J, Dagan T, Boucher Y, et al: Prokaryotic evolution and the tree of life are two different things. Biol Direct 2009;4:34.

Beiko RG, Harlow TJ, Ragan MA: Highways of gene sharing in prokaryotes. Proc Natl Acad Sci USA 2005; 102:14332-14337.

-Boucher Y, Douady CJ, Papke RT, Walsh DA, Boudreau MER, Nesbø CL, Case RJ, Doolittle WF: Lateral gene transfer and the origins of prokaryotic groups. Annu Rev Genet 2003;37:283-328.

- Bowler C, Allen AE, Badger JH, Grimwood J, Jabbari K, Kuo A, Maheswari U, Martens C, Maumus F, Otillar RP, et al: The Phaeodactylum genome reveals the evolutionary history of diatom genomes. Nature 2008;456: 239-244.

Brock DA, Gomer RH: A secreted factor represses cell proliferation in Dictyostelium. Development 2005;132:4553-4562.
Carlton JM, Hirt RP, Silva JC, Delcher AL, Schatz M, Zhao Q, Wortman JR, Bidwell SL, Alsmark UC, Besteiro S, et al: Draft genome sequence of the sexually transmitted pathogen Trichomonas vaginalis. Science 2007; 315:207-212.

Charlebois RL, Doolittle WF: Computing prokaryotic gene ubiquity: rescuing the core from extinction. Genome Res 2004;14:24692477.

-Ciccarelli FD, Doerks T, von Mering C, Creevey CJ, Snel B, Bork P: Toward automatic reconstruction of a highly resolved tree of life. Science 2006;311:1283-1287.

Dagan T, Martin W: The tree of one percent. Genome Biol 2006;7:118.

Dagan T, Martin W: Ancestral genome sizes specify the minimum rate of lateral gene transfer during prokaryote evolution. Proc Natl Acad Sci USA 2007;104:870-875.

$\checkmark$ De Jonckheere JF: A century of research on the amoeboflagellate genus Naegleria. Acta Protozool 2002;41:309-342.

Doolittle WF: You are what you eat: a gene transfer ratchet could account for bacterial genes in eukaryotic nuclear genomes. Trends Genet 1998;14:307-311.

Eichinger L, Noegel AA: Comparative genomics of Dictyostelium discoideum and Entamoeba histolytica. Curr Opin Microbiol 2005;8: 606-611.

-Eichinger L, Pachebat JA, Glöckner G, Rajandream MA, Sucgang R, Berriman M, Song J, Olsen R, Szafranski K, Xu Q, et al: The genome of the social amoeba Dictyostelium discoideum. Nature 2005;435:43-57.

Filée J, Siguier P, Chandler M: I am what I eat and I eat what I am: acquisition of bacterial genes by giant viruses. Trends Genet 2007;23:1015.

-Finn RD, Tate J, Mistry J, Coggill PC, Sammut SJ, Hotz HR, Ceric G, Forslund K, Eddy SR, Sonnhammer EL, et al: The Pfam protein families database. Nucleic Acids Res 2008; 36:D281-D288.

Franzén O, Jerlström-Hultqvist J, Castro E, Sherwood E, Ankarklev J, Reiner D, Palm D, Andersson JO, Andersson B, Svärd S: Draft genome sequencing of Giardia intestinalis assemblage B isolate GS: are human giardiasis caused by two different species? PLoS Pathog 2009;5:e1000560.

-Frickey T, Lupas AN: PhyloGenie: automated phylome generation and analysis. Nucleic Acids Res 2004;32:5231-5238.

Friesen TL, Stukenbrock EH, Liu Z, Meinhardt S, Ling H, Faris JD, Rasmussen JB, Solomon PS, McDonald BA, Oliver RP: Emergence of a new disease as a result of interspecific virulence gene transfer. Nat Genet 2006;38:953956.

Fritz-Laylin LK, Prochnik SE, Ginger ML, Dacks JB, Carpenter ML, Field MC, Kuo A, Paredez A, Chapman J, Pham J, et al: The genome of Naegleria gruberi illuminates early eukaryotic versatility. Cell 2010;140:631-642.
Guindon S, Gascuel O: A simple, fast, and accurate algorithm to estimate large phylogenies by maximum likelihood. Syst Biol 2003;52: 696-704.

Hackett JD, Yoon HS, Li S, Reyes-Prieto A, Rummele SE, Bhattacharya D: Phylogenomic analysis supports the monophyly of cryptophytes and haptophytes and the association of rhizaria with chromalveolates. Mol Biol Evol 2007;24:1702-1713.

Hall C, Brachat S, Dietrich FS: Contribution of horizontal gene transfer to the evolution of Saccharomyces cerevisiae. Eukaryot Cell 2005;4:1102-1115.

-Hampl V, Hug L, Leigh JW, Dacks JB, Lang BF, Simpson AG, Roger AJ: Phylogenomic analyses support the monophyly of Excavata and resolve relationships among eukaryotic 'supergroups'. Proc Natl Acad Sci USA 2009; 106:3859-3864.

Hampl V, Silberman JD, Stechmann A, Diaz-Trivino S, Johnson PJ, Roger AJ: Genetic evidence for a mitochondriate ancestry in the 'amitochondriate' flagellate Trimastix pyriformis. PLoS ONE 2008;3:e1383.

Huang J, Gogarten JP: Did an ancient chlamydial endosymbiosis facilitate the establishment of primary plastids? Genome Biol 2007; 8:R99.

Huang J, Gogarten JP: Concerted gene recruitment in early plant evolution. Genome Biol 2008;9:R109.

-Jain R, Yuen IS, Taphouse CR, Gomer RH: A density-sensing factor controls development in Dictyostelium. Genes Dev 1992;6:390400 .

Jerlström-Hultqvist J, Franzen O, Ankarklev J, $\mathrm{Xu}$ F, Nohynkova E, Andersson JO, Svärd SG, Andersson B: Genome analysis and comparative genomics of a Giardia intestinalis assemblage E isolate. BMC Genomics 2010; 11:543.

Keeling PJ: Functional and ecological impacts of horizontal gene transfer in eukaryotes. Curr Opin Gene Dev 2009;19:613-619.

Keeling PJ, Palmer JD: Horizontal gene transfer in eukaryotic evolution. Nat Rev Genet 2008; 9:605-618.

Kettler GC, Martiny AC, Huang K, Zucker J, Coleman ML, Rodrigue S, Chen F, Lapidus A, Ferriera S, Johnson J, et al: Patterns and implications of gene gain and loss in the evolution of Prochlorococcus. PLoS Genet 2007; 3:e231.

King N, Westbrook MJ, Young SL, Kuo A, Abedin M, Chapman J, Fairclough S, Hellsten U, Isogai Y, Letunic I, et al: The genome of the choanoflagellate Monosiga brevicollis and the origin of metazoans. Nature 2008;451: 783-788.

Lapierre P, Gogarten JP: Estimating the size of the bacterial pan-genome. Trends Genet 2009;25:107-110.

Lawrence JG, Ochman H: Amelioration of bacterial genomes: rates of change and exchange. J Mol Evol 1997;44:383-397. 
Lerat E, Daubin V, Ochman H, Moran NA: Evolutionary origins of genomic repertoires in bacteria. PLoS Biol 2005;3:e130.

- Li S, Nosenko T, Hackett JD, Bhattacharya D: Phylogenomic analysis identifies red algal genes of endosymbiotic origin in the chromalveolates. Mol Biol Evol 2006;23:663-674.

Loftus B, Anderson I, Davies R, Alsmark UCM, Samuelson J, Amedeo P, Roncaglia P, Berriman M, Hirt RP, Mann BJ, et al: The genome of the protist parasite Entamoeba histolytica. Nature 2005;433:865-868.

Moreira D, Brochier-Armanet C: Giant viruses, giant chimeras: the multiple evolutionary histories of Mimivirus genes. BMC Evol Biol 2008;8:12.

-Nosenko T, Bhattacharya D: Horizontal gene transfer in chromalveolates. BMC Evol Biol 2007; $7: 173$.

O'Brien EA, Koski LB, Zhang Y, Yang L, Wang E, Gray MW, Burger G, Lang BF: TBestDB: a taxonomically broad database of expressed sequence tags (ESTs). Nucleic Acids Res 2007;35:D445-D451.

- Parfrey LW, Grant J, Tekle YI, Lasek-Nesselquist E, Morrison HG, Sogin ML, Patterson DJ, Katz LA: Broadly sampled multigene analyses yield a well-resolved eukaryotic tree of life. Syst Biol 2010;59:518-533.

Ragan MA: Detection of lateral gene transfer among microbial genomes. Curr Opin Genet Dev 2001;11:620-626.

-Reyes-Prieto A, Hackett JD, Soares MB, Bonaldo MF, Bhattacharya D: Cyanobacterial contribution to algal nuclear genomes is primarily limited to plastid functions. Curr Biol 2006; 16:2320-2325.
Ricard G, McEwan NR, Dutilh BE, Jouany JP, Macheboeuf D, Mitsumori M, McIntosh FM, Michalowski T, Nagamine T, Nelson N, et al: Horizontal gene transfer from bacteria to rumen ciliates indicates adaptation to their anaerobic carbohydrates rich environment. BMC Genomics 2006;7:22.

Richards TA, Dacks JB, Jenkinson JM, Thornton CR, Talbot NJ: Evolution of filamentous plant pathogens: gene exchange across eukaryotic kingdoms. Curr Biol 2006;16:18571864.

Rogers MB, Watkins RF, Harper JT, Durnford DG, Gray MW, Keeling PJ: A complex and punctate distribution of three eukaryotic genes derived by lateral gene transfer. BMC Evol Biol 2007;7:89.

Seshadri R, Paulsen IT, Eisen JA, Read TD, Nelson KE, Nelson WC, Ward NL, Tettelin H, Davidsen TM, Beanan MJ, et al: Complete genome sequence of the Q-fever pathogen Coxiella burnetii. Proc Natl Acad Sci USA 2003;100:5455-5460.

-Stechmann A, Baumgartner M, Silberman JD, Roger AJ: The glycolytic pathway of Trimastix pyriformis is an evolutionary mosaic. BMC Evol Biol 2006;6:101.

Tatusov RL, Galperin MY, Natale DA, Koonin EV: The COG database: a tool for genomescale analysis of protein functions and evolution. Nucleic Acids Res 2000;28:33-36.

Temporini ED, VanEtten HD: An analysis of the phylogenetic distribution of the pea pathogenicity genes of Nectria haematococca MPVI supports the hypothesis of their origin by horizontal transfer and uncovers a potentially new pathogen of garden pea: Neocosmospora boniensis. Curr Genet 2004;46:29-36.
Tringe SG, von Mering C, Kobayashi A, Salamov AA, Chen K, Chang HW, Podar M, Short JM, Mathur EJ, Detter JC, et al: Comparative metagenomics of microbial communities. Science 2005;308:554-557.

-Van Der Wel H, Morris HR, Panico M, Paxton T, Dell A, Kaplan L, West CM: Molecular cloning and expression of a UDP-N-acetylglucosamine (GlcNAc):hydroxyproline polypeptide GlcNAc-transferase that modifies Skpl in the cytoplasm of Dictyostelium. J Biol Chem 2002;277:46328-46337.

Watkins RF, Gray MW: The frequency of eubacterium-to-eukaryote lateral gene transfers shows significant cross-taxa variation within amoebozoa. J Mol Evol 2006;63:801-814.

Welch RA, Burland V, Plunkett G 3rd, Redford P, Roesch P, Rasko D, Buckles EL, Liou SR, Boutin A, Hackett J, et al: Extensive mosaic structure revealed by the complete genome sequence of uropathogenic Escherichia coli. Proc Natl Acad Sci USA 2002;99:1702017024.

West CM: Evolutionary and functional implications of the complex glycosylation of Skp1, a cytoplasmic/nuclear glycoprotein associated with polyubiquitination. Cell Mol Life Sci 2003;60:229-240.

Wilkinson M, McInerney JO, Hirt RP, Foster PG, Embley TM: Of clades and clans: terms for phylogenetic relationships in unrooted trees. Trends Ecol Evol 2007;22:114-115.

-Yooseph S, Sutton G, Rusch DB, Halpern AL, Williamson SJ, Remington K, Eisen JA, Heidelberg KB, Manning G, Li W, et al: The Sorcerer II global ocean sampling expedition: expanding the universe of protein families. PLoS Biol 2007;5:e16. 